\title{
Atmospheric stability index using radio occultation refractivity profiles
}

\author{
D Jagadheesha ${ }^{1, *}$, B Manikiam ${ }^{2}$, Neerja Sharma ${ }^{3}$ and $\mathrm{P} \mathrm{K} \mathrm{PAL}^{4}$ \\ ${ }^{1}$ Atmospheric Science Programme, Indian Space Research Organization (ISRO) Head Quarters, \\ Bangalore 560 094, India. \\ ${ }^{2}$ Department of Physics, Tumkur University, Tumkur 572 102, India. \\ ${ }^{3}$ Atmospheric Sciences and Oceanography Group, National Remote Sensing Centre, \\ Balanagar, Hyderabad 500 625, India. \\ ${ }^{4}$ Meteorology and Oceanography Group, Remote Sensing Applications Area, \\ Space Applications Centre, Ahmedabad 380 015, India. \\ *e-mail:d_jagadish@rediffmail.com
}

A new stability index based on atmospheric refractivity at $\sim 500 \mathrm{hPa}$ level and surface measurements of temperature, pressure and humidity is formulated. The new index named here as refractivity based lifted index (RLI) is designed to give similar results as traditionally used lifted index derived from radiosonde profiles of temperature, pressure and humidity. The formulation of the stability index and its comparison with the traditional temperature profile based lifted index (LI) is discussed. The index is tested on COSMIC radio occultation derived refractivity profiles over Indian region. The forecast potential of the new index for rainfall on $2^{\circ} \times 2^{\circ}$ latitude-longitude spatial scale with lead time of $3-24$ hours indicate that the refractivity based lifted index works better than the traditional temperature based lifted index for the Indian monsoon region. Decreasing values of RLI tend to give increasing rainfall probabilities.

\section{Introduction}

Radio occultation measurements of refractivity profiles are known to give reasonably accurate humidity profiles of the atmosphere (Sokolovskiy 2001; Jensen et al 2003; Kuo et al 2004; Sokolovskiy et al 2006; Anthes et al 2008). Given the refractivity profiles, one can derive atmospheric temperature, pressure, and humidity profiles either by using 1-d variational assimilation method (e.g., Gorbunov and Sokolovskiy 1993; Healy and Eyre 2000; Palmer et al 2000; Gorbunov and Kornblueh 2003; von Engeln et al 2003) or by other methods which use surface or a lower level atmospheric temperature and pressure (O'Sullivan et al 2000;
Jagadheesha et al 2009). 1-d variational assimilation technique uses atmospheric temperature, pressure and humidity profiles from numerical model reanalysis/forecasts as a priori information. Typical estimates of relative humidity errors from the radio occultation in lower troposphere from these retrieval techniques are better than $\sim 15 \%$. Temperature retrieval errors vary between the techniques and validation studies indicate $1-\mathrm{d}$ variational assimilation technique gives reasonably better estimates of temperature with RMS erros better than $\sim 2 \mathrm{~K}$ (Jagadheesha et al 2009). Sharma et al (2009) used radio occultation temperature and humidity profiles retrieved from 1-d variational technique to study rainfall and its

Keywords. Radio occultation; lifted index; atmospheric stability; rainfall nowcasting. 
association with stability and moisture parameters over India and surrounding regions. They showed that an optimal combination of lifted index, total precipitable water and average relative humidity or average refractivity in the lower troposphere can indicate over $90 \%$ probability of rainfall. They used radio occultation derived temperature and humidity profiles, which reached at least $950 \mathrm{hPa}$ in lower troposphere so as to get reasonable estimates of precipitable water, average relative humidity, etc. In this study, the we address the possibility of using refractivity profile which is the basic measurement after bending angle from radio occultation to formulate a new atmospheric stability index in the lines similar to lifted index (Galway 1956). We note that refractivity from radio occultation is available at different heights rather than pressure levels. However, if one knows surface pressure and temperature, one can estimate pressure as a function of height using refractivity profile reasonably accurately using the technique given by O'Sullivan et al (2000). It is found that O'Sullivan et al (2000) technique gives very minimal errors in the estimation of pressure profiles (RMS error less than $2 \mathrm{hPa}$ around $500 \mathrm{hPa}$ level) from refractivity and almost similar to pressure profile retrieved from 1-d variational assimilation technique (Jagadheesha et al 2009). Once we fix refractivity profile in pressure coordinates rather than altitude, we use refractivity at $\sim 500 \mathrm{hPa}$ to formulate a new index of stability which contains information on lifted index and moisture at $\sim 500 \mathrm{hPa}$. Thus the index requires that radio occultation refractivity profiles be available at least up to $\sim 5 \mathrm{~km}$ in the lower troposphere. Unlike Sharma et al's (2009) study which addressed correspondence between rainfall and atmospheric stability and humidity parameters, our goal is to study the potential for short term predictability of cumulative rainfall from $3-$ 24 hours after the radio occultation measurement. We note here that such a study can also be done with radiosonde measurements of temperature and humidity profiles. However, most of the radiosonde network is limited to land areas and over the oceans coverage is inadequate. In such a scenario, it is feasible to use the information derived from satellite sounding techniques such as radio occultation. Many radio occultation measurements of refractivity profiles do not reach closer to the surface. In such a scenario, our objective is to use the information about surface meteorological parameters and refractivity at $500 \mathrm{hPa}$ to extract useful information on short-term rainfall predictability.

We use diverse radiosonde profiles used in the simulation studies for infrared sounders (Seemann et al 2003) to check the feasibility of deriving refractivity in vertical pressure coordinates and then discuss the formulation of refractivity based lifted index and its advantages over traditional temperature profile based lifted index. We estimate the new refractivity based lifted index using COSMIC profiles over India and surroundings for May-September months of 2008 and 2009 and compare it with temperature based lifted index in terms of its short term rainfall forecast potential.

\section{Formulation of refractivity based lifted index}

In traditional temperature profile based lifted index, environment temperature at $500 \mathrm{hPa}$ is compared with the temperature of an air parcel lifted adiabatically from the surface to lifting condensation level and pseudo adiabatically from lifting condensation level (LCL) to $500 \mathrm{hPa}$ (Galway 1956). It is assumed that the air parcel does not mix with the environment as it rises to different pressure levels from the surface. LCL pressure is given by the equation

$$
\mathrm{LCL}=\frac{S P(P T / S T)^{3.5}}{1000},
$$

where $S P$ is the surface pressure $(\mathrm{hPa}) ; S T$ is the surface temperature $(\mathrm{K})$; and $P T$ is the parcel temperature $(\mathrm{K})$. The parcel temperature $(P T)$ at LCL is given by the equation

$$
\begin{aligned}
P T= & ((1 /(1 /(S D P-56) \\
& +\log (S T / S D P) / 800))+56),
\end{aligned}
$$

where $S D P=$ surface dew point $(\mathrm{K})$.

Up to LCL, parcel temperature will change as per dry adiabatic lapse rate, which is constant with respect to height $\left(\sim 9.8 \mathrm{~K} \mathrm{~km}^{-1}\right)$. Above LCL, parcel temperature will change as per moist adiabatic lapse rate (MALR), which is given by

$$
\operatorname{MALR}=\Gamma_{d} \frac{\left(1+w_{s} L_{v} / R_{d} T\right)}{\left(1+w_{s} L_{v}^{2} / c_{p} R_{v} T^{2}\right)},
$$

where $\Gamma_{d}$ is the dry adiabatic lapse rate $\left(\sim 9.8 \mathrm{~K} \mathrm{~km}^{-1}\right), w_{s}$ is the saturation water vapour mixing ratio $(\mathrm{kg} / \mathrm{kg})$ at temperature $T(\mathrm{~K}), L_{v}$ is the latent heat of vapourization $\left(2.25 \times 10^{6} \mathrm{~J} \mathrm{~kg}^{-1}\right)$, $R_{d}$ the gas constant for dry air $\left(287.0 \mathrm{~J} \mathrm{~K}^{-1} \mathrm{~kg}^{-1}\right)$, $R_{v}$ the gas constant for water vapour (461.51 $\mathrm{J} \mathrm{K}^{-1} \mathrm{~kg}^{-1}$ ), and $c_{p}$ the specific heat for dry air at constant pressure (1004 $\left.\mathrm{J} \mathrm{K}^{-1} \mathrm{~kg}^{-1}\right)$. Above LCL, a warm and moist air parcel would have a lower lapse rate compared to dry adiabatic lapse rate due to release of latent heat of vapourization as water vapour condense to liquid in the 
parcel. Essentially the vertical profile of parcel temperature would be determined by the initial parcel temperature and water vapour mixing ratio. If the parcel is warmer (colder) than the surrounding environment, it would be buoyant (stable) and the environment is conducive (not conducive) to the development of convection to take place. Thus the traditional lifted index is an indicator of potential for convective activity. We note that the parcel temperature calculations are purely theoretical and it is only for the environment for which measurement exists. Thus as a parcel rises in equilibrium with the surrounding pressure, one can also use parcel refractivity and compare it with the environmental refractivity at different pressure levels and infer about the stability of the atmosphere. However, comparing refractivity of the parcel with that of surrounding environment is not feasible, as difference between parcel and environmental refractivity do not give a clue of whether the parcel is denser or lighter than the environment. Instead, we can try comparing 'dry' term of parcel refractivity with environmental refractivity. We know that the neutral atmospheric refractivity is of the form (Smith and Weintraub 1953):

$$
N=c_{1} \frac{P}{T}+c_{2} \frac{e}{T^{2}}
$$

where $c_{1}=77.6 \mathrm{~K} \mathrm{hPa}^{-1}$ and $c_{2}=373000.0 \mathrm{~K}^{2} \mathrm{hPa}^{-1}$ so that refractivity is a dimensionless parameter (referred as $N$ units in literature). $P$ is atmo- spheric pressure in $\mathrm{hPa}$ and $e$ is water vapour partial pressure in $\mathrm{hPa}$, and $T$ is temperature in $\mathrm{K}$. The first (second) term in the above equation for refractivity is known as dry term (wet term). As parcel temperature calculations are theoretical, we have knowledge of dry and wet terms for the parcel refractivity at each pressure level. At $500 \mathrm{hPa}$ we can consider the following index referred here afterwards as refractivity based lifted index (RLI) in $N$ units as an indicator of atmospheric stability.

$$
\begin{aligned}
& \mathrm{RLI}=-\left(N_{e}-N_{\text {pdry }}\right) \\
& \mathrm{RLI}=-\left[c_{1} \frac{500}{T_{e}}+c_{2} \frac{e}{T_{e}^{2}}-c_{1} \frac{500}{T_{p}}\right] \\
& \mathrm{RLI}=-\left[c_{1} \frac{500\left(T_{p}-T_{e}\right)}{T_{p} T_{e}}+c_{2} \frac{e}{T_{e}^{2}}\right] \\
& \mathrm{RLI}=c_{1} \frac{500 \cdot \mathrm{LI}}{T_{p} T_{e}}-c_{2} \frac{e}{T_{e}^{2}} .
\end{aligned}
$$

Here $N_{e}$ denotes environment refractivity at $500 \mathrm{hPa}, N_{\text {pdry }}$ denotes calculated parcel dry part of refractivity at $500 \mathrm{hPa}, T_{e}\left(T_{p}\right)$ denotes environmental (parcel) temperature (in K) at $500 \mathrm{hPa}$ and $e$ denotes environmental water vapour partial pressure (in $\mathrm{hPa}$ ) at $500 \mathrm{hPa}$. LI denotes the traditional temperature based lifted index (which is $T_{e}-T_{p}$ ). The calculation of the above index is possible if refractivity profile (in pressure coordinates) and pressure, temperature and water vapour mixing ratios at the surface (or a lower level where parcel

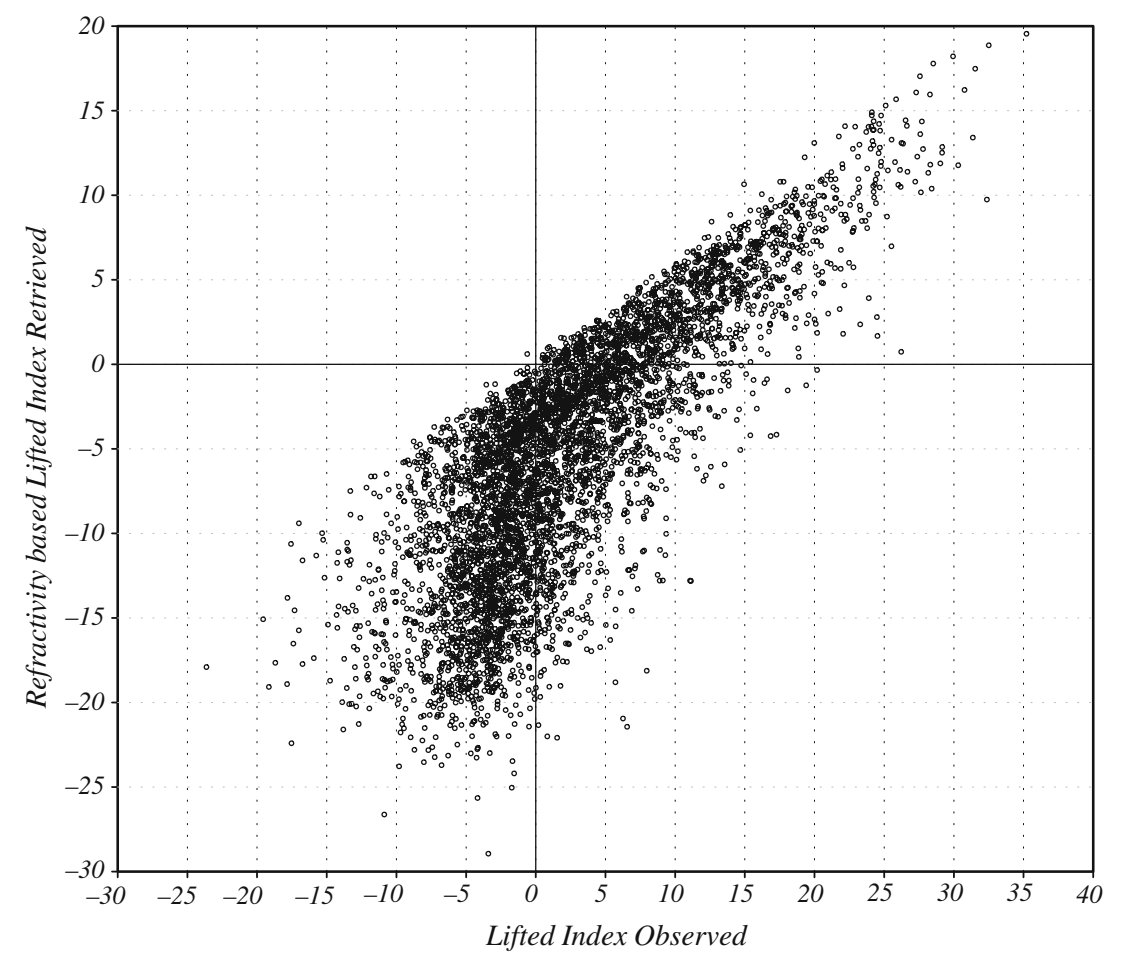

Figure 1. Scatter plot of LI vs. RLI for 5040 diverse radiosonde profiles over the tropics $\left(30^{\circ} \mathrm{S}-30^{\circ} \mathrm{N}\right)$. 
is assumed to be originated) are known. This formulation ensures that whenever the temperature based lifted index (LI) is negative RLI is also negative. However, if significant water vapour is present at $500 \mathrm{hPa}$, then whenever LI is positive, RLI can be negative. As we see later, that in most of the highly stable atmospheric cases, moisture in the upper troposphere is also very less and RLI retains same sign as LI in such cases. Thus the new index RLI makes minimal use of retrieved atmospheric parameters in inferring atmospheric stability.

Having formulated RLI, we now examine its retrievability compared to LI in radiosonde derived refractivity profiles. We use 5040 diverse radiosonde profiles over the tropics (between $30^{\circ} \mathrm{S}$ and $30^{\circ} \mathrm{N}$ ), which are used in infrared sounder
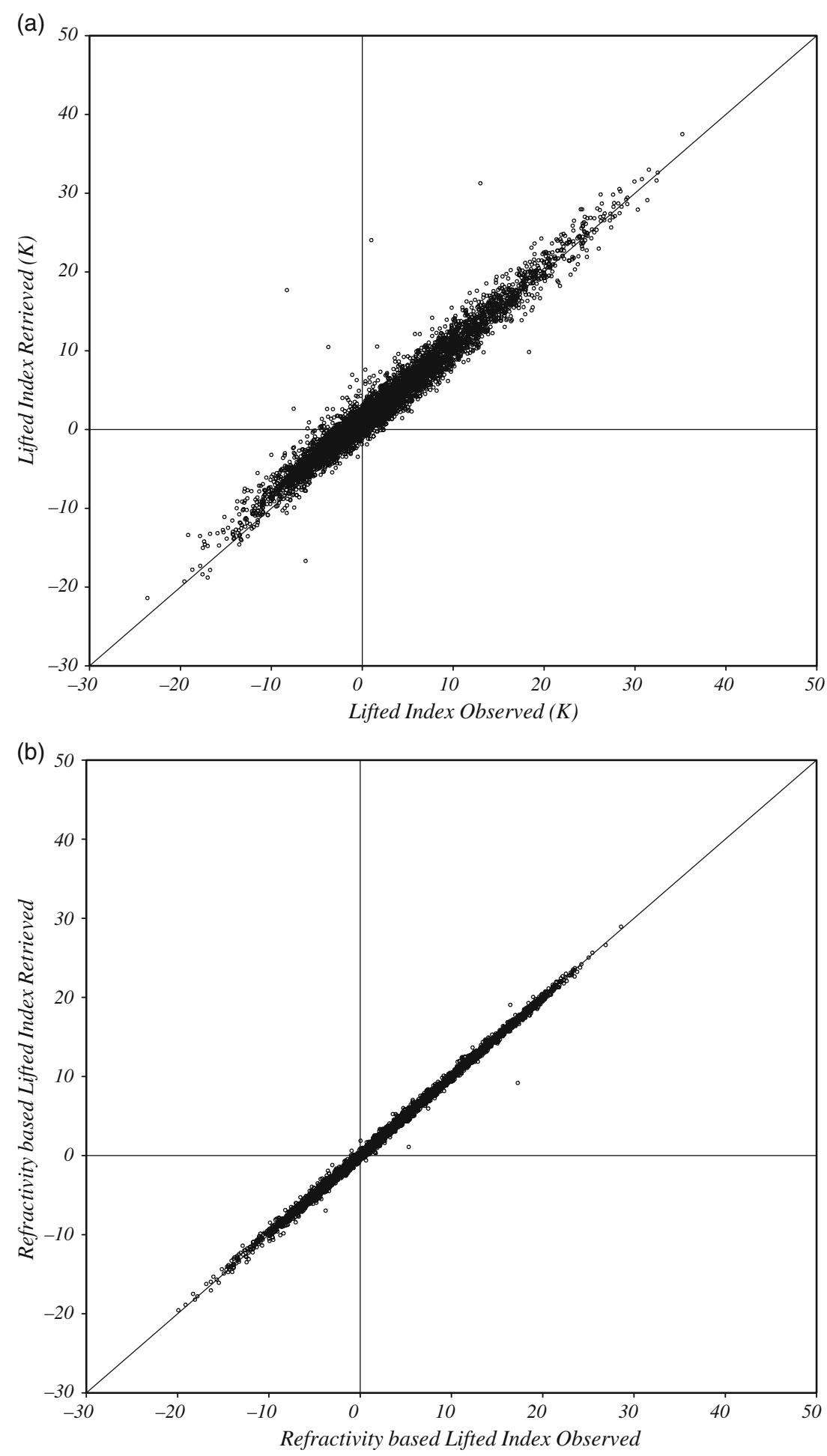

Figure 2. (a) Scatter plot of observed vs. retrieved LI. (b) Same as figure 2 except for RLI. 
algorithm development (Seemann et al 2003). We first obtained refractivity profile from radiosonde temperature, pressure and water vapour profiles. Having known surface or lower level pressure and temperature, we retrieved pressure, temperature and humidity profiles using the technique described in O'Sullivan et al (2000). Thus we have refractivity profiles in vertical coordinates of pressure. We calculated profiles of parcel temperature and humidity originating from the surface as it rises in equilibrium with the surrounding environment with temperatures changing adiabatically in order to calculate lifted index. From these parcel profiles of temperature and humidity, LI and RLI are calculated for these diverse radiosonde derived refractivity profiles. The level closest to $500 \mathrm{hPa}$ in these radiosonde data is $497.6 \mathrm{hPa}$. This is the level at which we calculated LI and RLI. Figure 1 shows the scatter plot of LI versus RLI for these radiosonde data. From figure 1 it is clear that for same value of $L I$, there can be a range of RLI values because of the varying environmental water vapour at $500 \mathrm{hPa}$. Thus RLI combines environmental water vapour information at $500 \mathrm{hPa}$ with atmospheric stability. For smaller value of LI, indicating somewhat stable atmospheric conditions, RLI values can be larger because of the presence of significant amount of water vapour at $500 \mathrm{hPa}$ level. For large positive LI values, RLI values are also positive indicating that environmental moisture is very small in these cases. It is clearly seen that RLI is negative when LI is negative. Figure 2(a and b) shows scatter plots of LI observed (calculated using actual environmental temperature at $\sim 500 \mathrm{hPa}$ ) and retrieved (calculated using retrieved environmental temperature using O'Sullivan et al (2000) method at $\sim 500 \mathrm{hPa}$ ) and RLI observed and retrieved for these radiosonde data. It is clear that RLI is better reproducible (or retrievable) product when compared to LI as it has no dependence on retrieved atmospheric temperature and humidity profiles. The correlation coefficient between LI (RLI) observed and retrieved is 0.84 (0.99). The uncertainty in RLI introduced due to assignment of retrieved pressure to each height in refractivity profile is small compared to uncertainty in LI, which depends on temperature retrieval errors.

\section{A case study using COSMIC profiles over India during 2009}

We took Constellation of Observing Satellites for Meteorology, Ionosphere, and Climate (COSMIC) observed refractivity profiles (http://cosmic-io. cosmic.ucar.edu) over India and surrounding
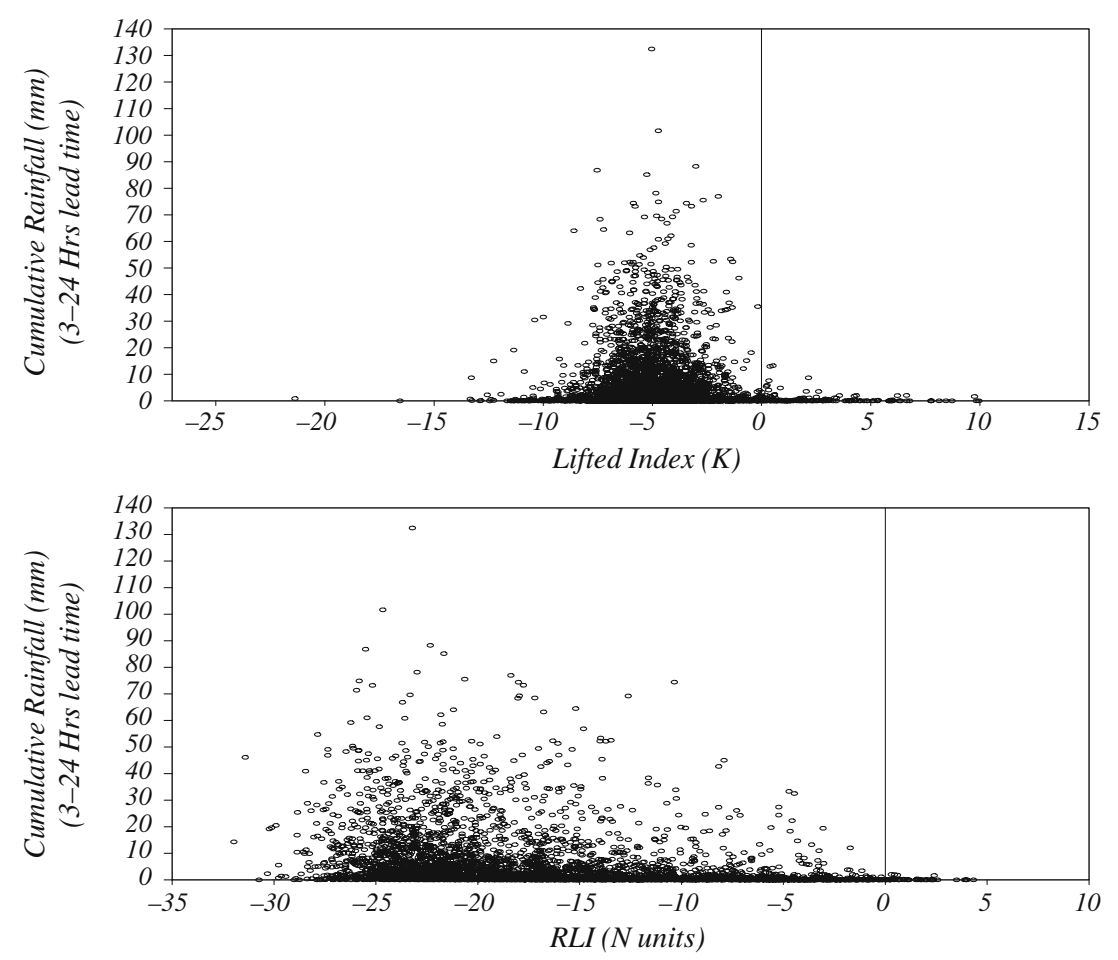

Figure 3. Scatter plot of LI (top panel) and RLI (bottom panel) with accumulated rainfall in a surrounding $2^{\circ} \times 2^{\circ}$ latitudelongitude area centered around lowest level tangent point of COSMIC radio occultations over India and surrounding region. 
region $\left(5^{\circ}-30^{\circ} \mathrm{N}\right.$ and $\left.65^{\circ}-95^{\circ} \mathrm{E}\right)$ during MaySeptember months for 2008 and 2009. We examine the rainfall forecast potential for both the indices calculated from COSMIC refractivity and 1-D var retrieved temperature profiles (Rocken et al 2000; Schreiner et al 2007; Anthes et al 2008). We used those profiles which reached at least $500 \mathrm{hPa}$ or lower to calculate LI and RLI. We took the available lowest level temperature, pressure and humidity from NCEP/NCAR reanalysis (Kistler et al 2000) subject to the condition that lowest level pressure is $950 \mathrm{hPa}$ or higher, as air parcel origin. We observed similar relationship between LI and RLI as seen in the previous section (not shown). Figure 3 shows scatter plot of LI and RLI with accumulated rainfall estimate from Tropical Rainfall Measurement Mission (TRMM) 3B42 version 6 (http://lake.nascom.nasa.gov/tovas, Nesbitt et al 2000; Huffmann et al 2003) in a box of $2^{\circ} \times 2^{\circ}$ latitude and longitude centered on the lowest level tangent point latitude and longitude of the COSMIC radio occultation event with a lead time of 3-24 hours. The top panel of figure 3 shows that most of the rainfall events coincided with negative LI values. However, there are a few rainy events even when the LI values are in the range $0-3$. One reason is that under these circumstances some water vapour may be present in the atmosphere and at a later time during the day favourable surface temperatures may have reached due to solar heating resulting in negative LI later. The bottom panel of figure 3 shows that almost all the rainy events occur when RLI is negative and less than zero in this case. Decreasing values of RLI indicate increased probability of rainfall. Tables 1 and 2 show the threshold values of LI and RLI and percentage of forthcoming rainy events in next 3-24 hours window in $2^{\circ} \times 2^{\circ}$ spatial scales. There is no tendency to observe increased rainfall events as LI becomes more negative. It is generally observed that LI indicates that the environment is supportive to convective events. In many cases, there may not be sufficient moisture in the atmosphere for the rainfall event to take place. Hence one cannot fix a suitable threshold for LI to link it with forthcoming rainfall. Sharma et al (2009) have shown that LI in combination with precipitable water and average refractivity in the lower troposphere gives useful results. In the case of RLI as its value decreases from 0 to -20 and below, percentage of rainfall events also increase. RLI has a term indicating environmental moisture at $500 \mathrm{hPa}$. More negative RLI indicates more moisture in the environment in addition to being supportive for convection. Hence we observe the tendency that percentage of rainfall events increase as RLI becomes more negative. Thus RLI works like an index, which takes into account convective instability of the atmosphere as well as some signature of moisture availability in the atmosphere. Thus in this case study, which
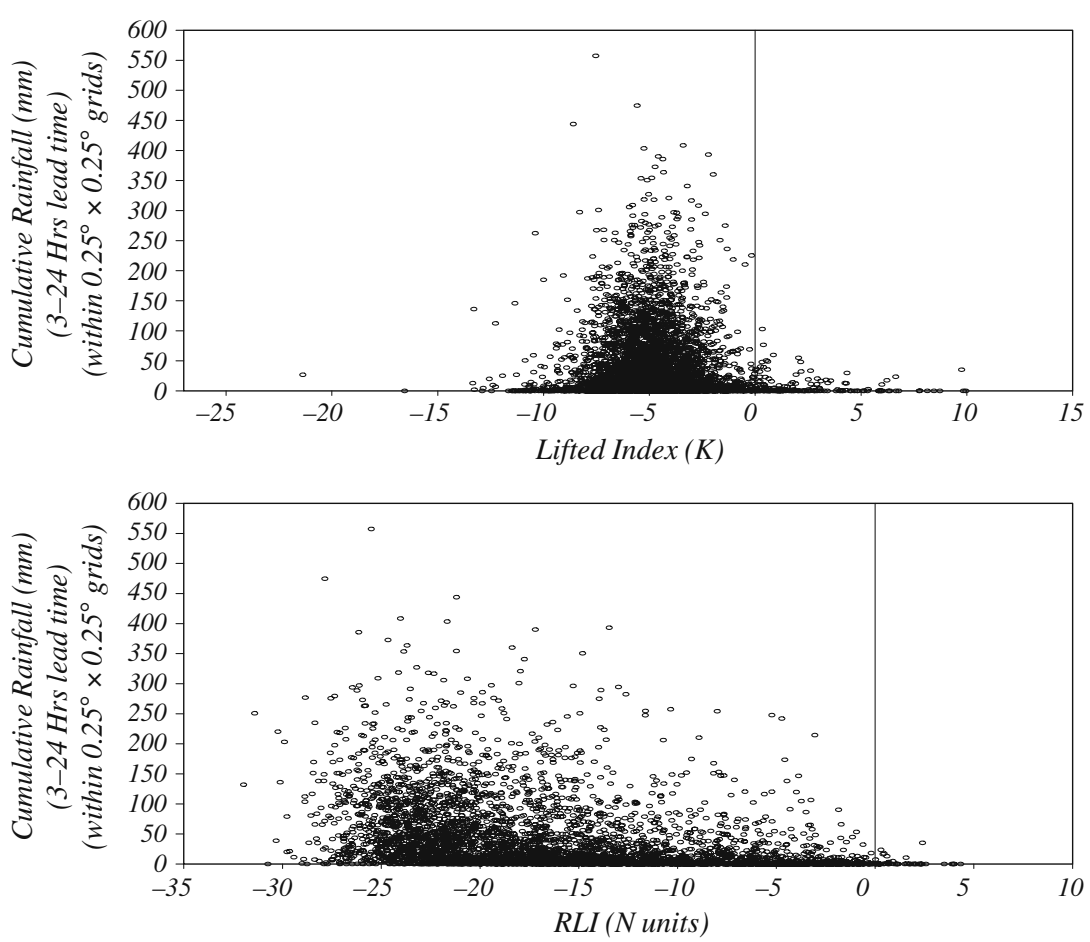

Figure 4. Same as figure 3 except that maximum rainfall in a $0.25^{\circ} \times 0.25^{\circ}$ grid within $2^{\circ} \times 2^{\circ}$ grid are added in $3-24$ hours time window after the occultation event. 
Table 1. Percent of rainfall events with accumulated rainfall range 2-10 $\mathrm{mm}$ and $>10 \mathrm{~mm}$ with 3-24 hours lead time for different thresholds in LI. Numerator (denomenator) in parenthesis indicates number of rainfall events (total number of events).

\begin{tabular}{lcr}
\hline LI thresholds & $\begin{array}{c}\text { of events with } 3-24 \text { hours } \\
\text { cumulative rainfall } \\
>2 \mathrm{~mm} \text { but } \leq 10 \mathrm{~mm}\end{array}$ & $\begin{array}{c}\text { \% of events with } 3-24 \text { hours } \\
\text { cumulative rainfall } \\
\leq 10 \mathrm{~mm}\end{array}$ \\
\hline 0 & $8.3(15 / 179)$ & $1.1(2 / 179)$ \\
$-2 \leq \mathrm{LI}<0$ & $12.9(35 / 271)$ & $9.22(25 / 271)$ \\
$-4 \leq \mathrm{LI}<-2$ & $23.7(215 / 907)$ & $16.1(146 / 907)$ \\
$-6 \leq \mathrm{LI}<-4$ & $26.35(478 / 1814)$ & $22.6(410 / 1814)$ \\
$\mathrm{LI}<-6$ & $19.7(234 / 1187)$ & $15.58(185 / 1187)$ \\
\hline
\end{tabular}

Table 2. Percent of rainfall events with accumulated rainfall range 2-10 $\mathrm{mm}$ and $>10 \mathrm{~mm}$ with 3-24 hours lead time for different thresholds in RLI. Numerator (denominator) in parenthesis indicates number of rainfall events (total number of events).

\begin{tabular}{lrr}
\hline & $\begin{array}{r}\text { \% of events with } 3-24 \text { hours } \\
\text { cumulative rainfall } \\
>2 \text { mm but } \leq 10 \mathrm{~mm}\end{array}$ & $\begin{array}{c}\% \text { of events with } 3-24 \text { hours } \\
\text { cumulative rainfall } \\
>10 \mathrm{~mm}\end{array}$ \\
\hline RLI thresholds & $0(0 / 51)$ & $0(0 / 51)$ \\
$-5 \leq \mathrm{RLI}<0$ & $4.88(20 / 409)$ & $2.2(9 / 409)$ \\
$-10 \leq \mathrm{RLI}<-5$ & $10.62(63 / 593)$ & $4.04(24 / 593)$ \\
$-20 \leq \mathrm{RLI}<-10$ & $21.35(1378 / 1836)$ & $13.23(243 / 1836)$ \\
$\mathrm{RLI}<-20$ & $34.10(935 / 1469)$ & $33.49(492 / 1469)$ \\
\hline
\end{tabular}

Table 3. Same as table 1 except for 3-24 hours maximum cumulative rainfall in a $0.25^{\circ} \times 0.25^{\circ}$ grid within $2^{\circ} \times 2^{\circ}$ grid.

\begin{tabular}{lccr}
\hline & $\begin{array}{c}\text { \% of maximum cumulative } \\
\text { rain in a smaller grid } \\
>5 \mathrm{~mm} \text { but } \leq 10 \mathrm{~mm}\end{array}$ & $\begin{array}{c}\text { \% of maximum cumulative } \\
\text { rain in a smaller grid } \\
>10 \mathrm{~mm} \text { but } \leq 20 \mathrm{~mm}\end{array}$ & $\begin{array}{c}\text { \% of maximum cumulative } \\
\text { rain in a smaller } \\
\text { grid thresholds }>20 \mathrm{~mm}\end{array}$ \\
\hline$\geq 0$ & $11.1(20 / 179)$ & $11.73(21 / 179)$ & $13.4(24 / 179)$ \\
$-2 \leq \mathrm{LI}<0$ & $12.9(35 / 271)$ & $12.29(22 / 179)$ & $43.57(78 / 179)$ \\
$-4 \leq \mathrm{LI}<-2$ & $6.04(58 / 907)$ & $11.5(105 / 907)$ & $46.4(421 / 907)$ \\
$-6 \leq \mathrm{LI} \leq 4$ & $7.49(136 / 1814)$ & $10.47(190 / 1814)$ & $53.7(975 / 1814)$ \\
$\mathrm{LI}<-6$ & $7.7(92 / 1187)$ & $11.54(137 / 1187)$ & $40.94(486 / 1187)$ \\
\hline
\end{tabular}

Table 4. Same as table 2 except for 3-24 hours maximum cumulative rainfall in a $0.25^{\circ} \times 0.25^{\circ}$ grid within $2^{\circ} \times 2^{\circ}$ grid.

\begin{tabular}{lccc}
\hline & $\begin{array}{c}\text { \% of maximum cumulative } \\
\text { rain in a smaller grid } \\
>5 \mathrm{~mm} \text { but } \leq 10 \mathrm{~mm}\end{array}$ & $\begin{array}{c}\text { \% of maximum cumulative } \\
\text { rain in a smaller grid } \\
>10 \mathrm{~mm} \text { but } \leq 20 \mathrm{~mm}\end{array}$ & $\begin{array}{c}\text { \% of maximum cumulative } \\
\text { rain in a smaller grid } \\
>20 \mathrm{~mm}\end{array}$ \\
\hline$\geq 0$ & $0(0 / 51)$ & $7.8(4 / 51)$ & $3.9(2 / 51)$ \\
$-5 \leq \mathrm{RLI}<0$ & $6.35(26 / 409)$ & $5.13(21 / 409)$ & $10.75(44 / 409)$ \\
$-10 \leq \mathrm{RLI}<-5$ & $6.9(41 / 593)$ & $11.63(69 / 593)$ & $20.57(122 / 593)$ \\
$-20 \leq \mathrm{RLI}<-10$ & $10.02(184 / 1836)$ & $12.9(237 / 1836)$ & $40.2(738 / 1836)$ \\
$\mathrm{RLI}<-20$ & $5.17(76 / 1469)$ & $9.73(143 / 1469)$ & $73.38(1078 / 1469)$ \\
\hline
\end{tabular}

is over India and the surrounding regions, RLI, appears to be a useful index of forthcoming rainfall event, though on a much larger spatial scale $\left(2^{\circ} \times 2^{\circ}\right.$ latitude longitude grids). This is because the radio occultation technique being a limb sounding technique has an inherent limitation of spatial resolution. However, with this information and smaller spatial scale information related to atmospheric moisture, one can try achieving a better rainfall nowcasting on a higher spatial resolution.

Next we examine smaller scale rainfall features within $2^{\circ} \times 2^{\circ}$ grids. For this we calculate maximum rainfall out of $640.250^{\circ} \times 0.250^{\circ}$ for $3-24$ hours duration after the occultation event. This quantity 
indicates maximum rainfall a $0.250^{\circ} \times 0.250^{\circ}$ grid would have received in 3-24 hours duration. It is also a measure of isolated heavy rainfall in smaller area within the larger grid. Figure 4 shows scatter plot of this maximum rainfall versus LI (top panel of figure 4) and RLI (bottom panel of figure 4). Tables 3 and 4 gives the probability of maximum cumulative rainfall for different LI and RLI ranges. Table 4 clearly shows that as RLI decreases incidences of heavy rainfall over a smaller area increase. LI do not show such clear tendency, as we are not examining it with other parameters such as total precipitable water, etc. Here we have not given cumulative rainfall less than $5 \mathrm{~mm}$. If we include them, rainfall probability can be as high as $95 \%$ for RLI less than -20 .

\section{Summary and discussions}

We have formulated a new index of atmospheric stability, which can be derived from a profile of refractivity. In radio occultation technique, refractivity is usually available as a function of altitude. With the available information on surface or a lower level pressure, temperature, and humidity, we can apply O'Sullivan et al (2000) technique to get refractivity as a function of pressure. Then we can apply parcel theory calculations to get parcel 'dry' refractivity at $\sim 500 \mathrm{hPa}$ and calculate RLI which is related to LI as described in section 2 . When applied on refractivity profiles derived from a large number of diverse radiosonde data over the tropics, it is found that RLI is better reproducible than LI. In the case study over India and surrounding regions, RLI appears to be a better indicator of forthcoming rainfall events as compared to LI. This is expected, as RLI is also an indicator of environmental moisture at $500 \mathrm{hPa}$ in addition to atmospheric instability. In this case study, decrease in LI though indicates increasing atmospheric instability do not necessarily translate to increase in rainfall events. On the other hand, decrease in RLI do show increase in rainfall events with increasing possibility of heavy rainfalls. When radiosonde and other atmospheric data are unavailable or partially available, RLI is an additional useful information for rainfall nowcasting. In India automatic weather stations (AWS) are increasingly becoming available with Indian Space Research Organization (ISRO) deploying over 950 AWS spread over the entire country. India Meteorological Department (IMD) too has plans of deploying over 1000 AWS spread over the country in near future. Future Indian satellite missions such as Megha-Tropiques will be giving increasing coverage of radio occultation measurements over the tropical region. Surface measurements required for RLI can come from AWS and radio occultation refractivity profiles from Indian and global missions like COSMIC making RLI estimations and study of its usefulness over the Indian region in near real time a good possibility.

\section{Acknowledgements}

The authors would like to thank COSMIC (http:// cosmic-io.cosmic.ucar.edu) and TRMM (http:// nascom.nasa.gov/tovas) websites for refractivity profiles and rainfall data, respectively. We thank Chairman and Scientific Secretary, Indian Space Research Organization for the support and encouragement. We also thank the four anonymous reviewers for their helpful comments.

\section{References}

Anthes R A and Coauthors 2008 The COSMIC/ FORMOSAT-3 mission: Early results; Bull. Amer. Meteor. Soc. 89 313-333.

Galway J G 1956 The lifted index as a predictor of latent instability; Bull. Amer. Meteor. Soc. 37 528-529.

Gorbunov M E and Sokolovskiy S 1993 Remote sensing of refractivity from space for global observations of atmospheric parameters; Max Planck Institute for Meteorology Rep. 199, 58 pp.

Gorbunov M E and Kornblueh L 2003 Principles of variational assimilation of GNSS radio occultation data; Max Planck Insitute for Meteorology Rep. 350, 34 pp.

Healy S and Eyre J 2000 Retrieving temperature, water vapor and surface pressure information from refractiveindex profiles derived by radio occultation: A simulation study; Quart. J. Roy. Meteor. Soc. 126 1661-1683.

Huffman G J, Adler R F, Stocker E F, Bolvin D T and Nelkin E J 2003 Analysis of TRMM three-hourly multi satellite precipitation estimates computed in real and post-real time; Combined preprints CD-ROM, 83rd AMS annual meeting Paper P4.11 in 12th Conference on Satellite Meteorology and Oceanography, 9-13 February 2003, Long Beach, CA, 2003.

Jagadheesha D, Simon B, Pal P K, Joshi P C and Maheshwari A 2009 A new technique for estimation of lower-tropospheric temperature and water vapor profiles from radio occultation refractivity; J. Atmos. Oceanic Technol. 26 1075-1089.

Jensen A S, Lohmann M S, Benson H-H and Nielsen A S 2003 Full spectrum inversion of radio occultation signals; Radio Sci. 38 1040, doi: 10.1029/2002RS0027/63.

Kistler R, Kalnay E and Coauthors 2000 The NCEP/NCAR 50-year Reanalysis; Bull. Amer. Meteor. Soc. 82 247-267.

Kuo Y-H, Wee T-K, Sokolovskiy S, Rocken C, Schreiner W, Hunt D and Anthes R A 2004 Inversion and error estimation of GPS radio occultation data; J. Meteor. Soc. Japan 82 507-531.

Nesbitt S W, Zipser E J and Cecil D J 2000 A census of precipitation features in the tropics using TRMM: Radar, ice scattering, and lightning observations; J. Climate (USA) 134087.

O'Sullivan D B, Herman B M, Feng D, Flittner D E and Ward D M 2000 Retrieval of water vapor profiles from GPS/MET radio occultations; Bull. Amer. Meteor. Soc. 81 1031-1040. 
Palmer P, Barnett J, Eyre J and Healy S 2000 A non-linear optimal estimation inverse method for radio occultation measurements of temperature, humidity, and surface pressure; J. Geophys. Res. 105 17,513-17,526.

Rocken C, Kuo Y H, Schreiner W, Hunt D, Sokolovskiy $\mathrm{S}$ and McCormick C 2000 COSMIC system description; Terr. Atmos. Oceanic Sci. 11 21-52.

Schreiner W, Rocken C, Sokolovskiy S, Syndergaard S and Hunt D 2007 Estimates of the precision of GPS radio occultations from the COSMIC/FORMOSAT-3 mission; Geophys. Res. Lett. 34 L04808, doi: 10.1029/ 2006GL027557.

Seemann S W, Li J, Menzel W P and Gumley L E 2003 Operational retrieval of atmospheric temperature, moisture, and ozone profiles from MODIS infrared sounders; J. Appl. Meteorol. 42 1072-1091.

Sharma N, Jagadheesha D, Joshi P C and Pal P K 2009 Atmospheric stability estimation using radio occultation data over India and surrounding region; Indian J. Radio Space Phys. 38 317-325.

Smith E L and Weintraub S 1953 The constants in the equation for atmospheric refractive index at radio frequencies; Proc. IRE 41 1035-1037.

Sokolovskiy S 2001 Tracking tropospheric radio occultation signals from low earth orbit; Radio Sci. 36 483498.

Sokolovskiy S, Rocken C, Hunt D, Schreiner W, Johnson J, Masters D and Esterhuizen S 2006 GPS profiling of the lower troposphere from space: Inversion and demodulation of the open loop radio occultation signals; Geophys. Res. Lett. 33 L14816, doi: 10.1029/2006GL026112.

Von Engeln A, Nedoluha G, Kirchengast G and Buhler S 2003 One dimensional variational (1-D Var) retrieval of temperature, water vapor, and a reference pressure from radio occultation measurements: A sensitivity analysis; J. Geophys. Res. 108 4337-4349. 